\title{
CARACTERIZAÇÃO DE BAUXITA ATIVADA ANTES E DEPOIS DA SATURAÇÃO COM ÓLEO MINERAL ISOLANTE
}

Josélia Ednar Antunes Piluski

Eletrosul Centrais Elétricas S.A., São José - SC, Brasil

Dachamir Hotza*

Departamento de Engenharia Química, Universidade Federal de Santa Catarina, 88040-900 Florianópolis - SC, Brasil

Recebido em 9/10/07; aceito em 30/11/07; publicado na web em 8/7/08

\begin{abstract}
CHARACTERIZATION OF ACTIVATED BAUXITE BEFORE AND AFTER SATURATION WITH INSULATING MINERAL OIL.
A characterization of activated bauxite and of activated bauxite impregnated with insulating mineral oil was made. The activated bauxite is used as adsorbent material in percolators during the regeneration of insulating mineral oil. After regeneration an insulating mineral oil is obtained with physical and chemical characteristics similar to those of the new oil. Moreover, saturated activated bauxite impregnated with insulating mineral oil is also produced. It is a dangerous residue according to NBR 10004 (Class I) and, thus, harmful to the environment. An alternative use of this waste in the ceramic industry is discussed.
\end{abstract}

Keyworks: activated bauxite; insulating mineral oil; waste recycling.

\section{INTRODUÇÃO}

O óleo mineral isolante é um derivado do petróleo, constituído principalmente por hidrocarbonetos e utilizado em equipamentos elétricos (transformadores, reatores, comutadores, disjuntores). $\mathrm{O}$ processo de oxidação do óleo tem início quando o oxigênio nele dissolvido reage com os hidrocarbonetos instáveis, na presença de catalisadores existentes nos equipamentos (cobre e ferro, principalmente). Este processo de oxidação é acelerado quando o equipamento entra em operação, devido às perdas dielétricas que se convertem em calor, ocasionando a degradação térmica. ${ }^{1,2}$

Os produtos finais resultantes são compostos ácidos e, em um estágio mais avançado de oxidação, há a formação de borra, que se deposita nos trocadores de calor e na parte ativa dos equipamentos. Estes depósitos dificultam o processo de convecção do óleo e a troca térmica do sistema espira/óleo, resultando em superaquecimento, diminuindo, assim, a eficiência do sistema de isolamento óleo/papel e, conseqüentemente, a vida útil do equipamento. ${ }^{3-6}$

A regeneração do óleo mineral isolante é definida como um processo que elimina, por métodos químicos e/ou por adsorção, contaminantes ácidos e coloidais e produtos de deterioração do óleo, de forma a se obter um produto com características similares às do óleo novo. A regeneração do óleo mineral isolante com bauxita (embora não se trate de um mineral, mas sim de um minério, esse é um termo mais usual que "bauxito"), ${ }^{7}$ como meio adsorvente, recupera as características físico-químicas originais do óleo removendo seus produtos de oxidação. Após o processo de regeneração, a bauxita saturada fica impregnada com óleo mineral isolante e seu descarte final é feito em aterros industriais.

A bauxita ativada é preparada pelo tratamento térmico do minério bauxita, que possui, no seu estado natural, um poder descorante muito reduzido. ${ }^{7}$ As bauxitas só atuam como descorantes de óleos se o hidróxido de alumínio que contêm for transformado em alumina- $\gamma$, de elevadas propriedades catalíticas e descorantes. A bauxita selecionada é secada entre 100 e $150{ }^{\circ} \mathrm{C}$, separada em

*e-mail: dhotza@gmail.com peneiras, moída e de novo separada em peneiras, de modo a se obter o máximo de material granulado para percolação. É calcinada, a seguir, em temperaturas entre 350 e $860^{\circ} \mathrm{C}$. Na percolação de óleos, a bauxita saturada pode ser reativada por tratamento com solventes, vapor d'água e calcinação; que pode ser repetido centena de vezes sem perda apreciável do poder descorante da bauxita ativada. ${ }^{8}$

Após sua vida útil na regeneração de óleo mineral isolante, seguindo a legislação em vigor, a bauxita é normalmente descartada. Em se tratando de um resíduo sólido, são observadas as normas brasileiras de classificação e gerenciamento, de resíduos sólidos (NBR 10004). ${ }^{9}$ Essa norma classifica os resíduos sólidos quanto aos seus riscos potenciais ao meio ambiente e à saúde pública para que os resíduos possam ser manuseados e destinados adequadamente. Para sua aplicação, é necessário dispor das normas NBR $10005^{10}$ (lixiviação de resíduos), NBR $10006^{11}$ (solubilização de resíduos) e NBR $10007^{12}$ (amostragem de resíduos).

A destinação final de resíduos industriais normalmente é o aterro industrial, o que gera vários inconvenientes ambientais e, além disso, desperdiça um material que pode ser reutilizado e reciclado, proporcionando melhorias significativas do ponto de vista ambiental. A futura utilização da bauxita impregnada com óleo mineral isolante poderá ser uma alternativa vantajosa do ponto de vista de gerenciamento de resíduos, pois transforma a bauxita calcinada impregnada com óleo mineral isolante em matéria-prima.

O objetivo deste trabalho foi caracterizar uma bauxita ativada antes e depois de sua utilização como adsorvente de óleos isolantes elétricos. Com base nesta caracterização, foi avaliada a eventual possibilidade de reutilização do resíduo de bauxita, visando reduzir o impacto negativo causado ao meio ambiente.

\section{PARTE EXPERIMENTAL}

\section{Material}

A bauxita estudada neste trabalho é proveniente da Mineradora Curimbaba (Poços de Caldas, MG). A amostragem da bauxita ati- 
vada e da bauxita impregnada com óleo mineral isolante foi realizada por quarteamento, sendo a primeira amostra acondicionada em embalagens de $60 \mathrm{~kg}$ e a segunda, em tambores abertos. Diversas análises laboratoriais foram realizadas com a finalidade de caracterizar as amostras e averiguar a potencialidade de seu uso em aplicações na indústria cerâmica.

\section{Análises}

A análise por fluorescência de raios-X (Phillips, modelo PW 2400 , com tubo de $3 \mathrm{~kW}$ e alvo de Rh) para a amostra de bauxita ativada foi realizada no Centro de Tecnologia em Materiais (CTCmat, Criciúma, SC), objetivando identificar e quantificar os compostos presentes a partir do resíduo de perda ao fogo a 1000 ${ }^{\circ} \mathrm{C}$. A análise por difração de raios-X foi realizada no Centro de Caracterização e Desenvolvimento de Materiais (CCDM/UFSCar, São Carlos, SP), em um difratômetro Philips (Xpert, com tubo de $\mathrm{Cu}-\mathrm{K} \alpha)$ ). A amostra foi moída em almofariz e analisada com o comprimento de onda do cobre, $\lambda=1,54056 \AA$, amostra rotacional, intervalo de medida em $2 \theta$ de 15 a $80^{\circ}$.

$\mathrm{Na}$ amostra de bauxita ativada impregnada com óleo mineral isolante foi realizado o ensaio de classificação de resíduos sólidos, segundo a norma NBR 10.004, ${ }^{9}$ no laboratório Tasqa (Paulínia, SP). Para a realização das análises foram empregadas as técnicas de espectrometria de absorção atômica, espectrometria de emissão de plasma, espectrometria de visível, titulometria potenciométrica e visual e gravimetria. ${ }^{10-12}$

A densidade foi medida pelo método de picnometria líquida no CTCmat (Criciúma, SC). A análise de distribuição granulométrica foi também realizada no CTCmat, por peneiramento a seco, utilizando peneiras de 16, 20, 60, 115 e 270 mesh.

A determinação de área superficial (BET) foi realizada no CCDM (São Carlos, SP), no equipamento Gemini 2370 da Micromeritics. A análise de porosimetria por intrusão de mercúrio foi também realizada no CCDM, no equipamento PoroSizer 9320 da Micromeritics. Ambas as amostras foram previamente secas em estufa a $75^{\circ} \mathrm{C}$ durante $2 \mathrm{~h}$.

$\mathrm{O}$ teste de atividade de azobenzeno para argilas foi realizado no Laboratório Físico-Químico (LAFIQ/Eletrosul, São José, SC). Neste ensaio, utilizou-se uma amostra de bauxita ativada com teor de umidade igual a $2 \%$ e outra amostra que permaneceu em estufa a $100^{\circ} \mathrm{C}$ por $20 \mathrm{~h}$.

A microscopia eletrônica de varredura (MEV) foi realizada no Laboratório de Materiais (Labmat/UFSC, Florianópolis, SC), em um equipamento Phillips XL 30, com o objetivo de observar a microestrutura e realizar análise química pontual das amostras através da microssonda acoplada de espectroscopia de energia dispersiva (EED). As amostras de bauxita ativada e bauxita ativada impregnada com óleo mineral isolante foram preparadas segundo técnicas utilizadas em ceramografia. Foram embutidas a frio com resina de poliéster para facilitar o manuseio, lixadas com lixas de carbeto de silício 120, 240, 320, 400 e 600 mesh, e polidas com pasta de diamante para obter uma superfície plana e livre de riscos. Após este preparo, foram recobertas com fino filme de ouro e levadas então para MEV.

As análises térmica diferencial (ATD) e termogravimétrica (TG) foram realizadas no CCDM (São Carlos, SP), em um equipamento Netzsch ST 409C. A amostra foi submetida à secagem em uma estufa a aproximadamente $50{ }^{\circ} \mathrm{C}$ e, em seguida, quantidades suficientes das mesmas foram inseridas nos porta-amostras para o referido ensaio. A faixa de temperatura utilizada foi de 25 a $1400{ }^{\circ} \mathrm{C}$, a uma taxa de aquecimento de $10{ }^{\circ} \mathrm{C} / \mathrm{min}$.

As curvas de gresificação foram obtidas para a amostra de bauxita ativada a partir de moagem a úmido, com resíduo entre 0,5 a 1,5\% (325 mesh), umidade de compactação de 7\%, pressão de compactação de $240 \mathrm{kgf} / \mathrm{cm}^{2}$ e patamar de queima de $4 \mathrm{~min}$, em diferentes temperaturas, conforme procedimento usual. ${ }^{13}$

\section{RESULTADOS E DISCUSSÃO}

\section{Composição química e de fases}

$\mathrm{Na}$ análise de fluorescência de raios-X, Tabela 1, detectou-se grande concentração de $\mathrm{Al}_{2} \mathrm{O}_{3}, 75,29 \%$ em massa, 10,04\% de $\mathrm{SiO}_{2}$ e $7,35 \%$ de $\mathrm{Fe}_{2} \mathrm{O}_{3}$. A concentração de $\mathrm{Fe}_{2} \mathrm{O}_{3}$ confere à bauxita a coloração vermelha. As bauxitas variam muito em propriedades físicas, mesmo apresentando igual teor de $\mathrm{Al}_{2} \mathrm{O}_{3}$. A cor das bauxitas depende do teor de ferro e de outras impurezas presentes, sendo as mais comuns as bauxitas vermelhas, ricas em óxidos e hidróxidos de ferro e pobres em sílica; as bauxitas brancas e cinzas, pobres em ferro e ricas em sílica, e as bauxitas marrons, ricas em ferro e pobres em sílica, com teor apreciável em matéria orgânica, que podem ser classificadas também como argilas aluminosas.

Tabela 1. Composição química, em óxidos, da bauxita ativada

\begin{tabular}{lc}
\hline Compostos & \% em massa \\
\hline $\mathrm{SiO}_{2}$ & 10,04 \\
$\mathrm{Al}_{2} \mathrm{O}_{3}$ & 75,29 \\
$\mathrm{Na}_{2} \mathrm{O}$ & 0,03 \\
$\mathrm{~K}_{2} \mathrm{O}$ & 0,10 \\
$\mathrm{CaO}$ & 0,11 \\
$\mathrm{MgO}$ & $\mathrm{N} . \mathrm{D}$. \\
$\mathrm{Fe}_{2} \mathrm{O}_{3}$ & 7,35 \\
$\mathrm{MnO}_{\mathrm{TiO}_{2}}$ & 0,36 \\
$\mathrm{P}_{2} \mathrm{O}_{5}$ & 0,88 \\
$\mathrm{Perda}$ ao fogo & 0,08 \\
\hline
\end{tabular}

Os demais compostos presentes apresentam concentração abaixo de $1 \%$. $\mathrm{CaO}, \mathrm{MgO}, \mathrm{Na}_{2} \mathrm{O}$ e $\mathrm{K}_{2} \mathrm{O}$ são agentes fundentes e tendem a baixar a refratariedade. Para concentrações abaixo de $1 \%$ de óxido de titânio, $\mathrm{TiO}_{2}$, não há praticamente alteração nas propriedades tecnológicas das argilas. ${ }^{7}$ A perda ao fogo de $3,46 \%$ é devida à ativação (calcinação) da bauxita, que não foi completa. ${ }^{14}$

Bauxitas refratárias devem possuir alto teor de alumina (mínimo de $61 \%$ após calcinação) e baixo teor de óxido de ferro (máximo de $2 \%$ após calcinação). ${ }^{14-16}$ A bauxita analisada apresenta um teor relativamente alto de $\mathrm{Fe}_{2} \mathrm{O}_{3}(7,35 \%)$, que descarta o seu uso como matéria-prima para produtos refratários. No entanto, as quantidades baixas de óxidos alcalinos $\left(\mathrm{Na}_{2} \mathrm{O}\right.$ e $\mathrm{K}_{2} \mathrm{O}$ em torno de $0,1 \%$ cada), a caracterizam como matéria-prima refratária para porcelana elétrica, por exemplo. ${ }^{17}$

As transformações de estrutura cristalina com a temperatura e a solubilidade em soluções de hidróxido de sódio dependem da natureza do óxido de alumínio hidratado existente nas bauxitas. ${ }^{7}$ As bauxitas são classificadas pelo tipo de hidróxido de alumínio presente em bauxitas gibsíticas, diaspóricas ou boemíticas. As bauxitas brasileiras conhecidas até o presente são todas gibsíticas. ${ }^{18}$

Pela análise mineralógica por difratometria de raios- $\mathrm{X}$ da bauxita ativada, Figura 1, foram identificadas as fases gibsita, boemita, óxido de alumínio e hematita. A amostra de bauxita ativada impregnada com óleo mineral isolante apresentou o mesmo perfil de difração. Não foi identificada nenhuma fase de aluminossilicato, embora tenha sido confirmada a presença de $\mathrm{Si}$ por EED, Tabela 2. A baixa intensidade e a baixa resolução das 


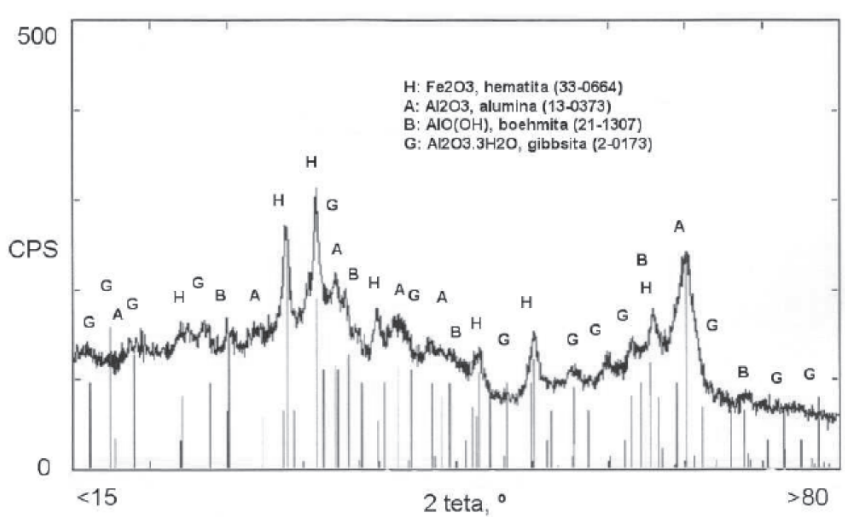

Figura 1. DRX da bauxita ativada

Tabela 2. Análise química por EED de amostra de bauxita (ver Figura 2)

\begin{tabular}{lcccc}
\hline Elemento & \multicolumn{4}{c}{ Percentual $(\mathrm{m} \%)$ nas regiões da micrografia } \\
& Branca & Cinza/branca & Cinza escuro & Cinza claro \\
\hline $\mathrm{O}$ & 9,10 & 15,01 & 23,25 & 13,18 \\
$\mathrm{Al}$ & 6,42 & 19,52 & 76,75 & 14,47 \\
$\mathrm{Si}$ & 3,06 & 23,14 & & 2,00 \\
$\mathrm{Ce}$ & 68,12 & 27,01 & & \\
$\mathrm{Mn}$ & 5,56 & 3,53 & & 66,35 \\
$\mathrm{Fe}$ & 7,74 & 4,50 & & \\
$\mathrm{~K}$ & & 7,30 & & 4,00 \\
$\mathrm{Ti}$ & & & & \\
\hline
\end{tabular}

linhas de difração indicam ser um material pouco cristalino, devido a seu tratamento térmico (calcinação). A presença de 5 a $8 \%$ de fase amorfa em bauxitas tem sido relatada na literatura. ${ }^{19}$

\section{Micrografia e microanálise}

A análise química pontual da amostra de bauxita ativada foi realizada numa micrografia obtida por MEV, Figura 2, onde po-

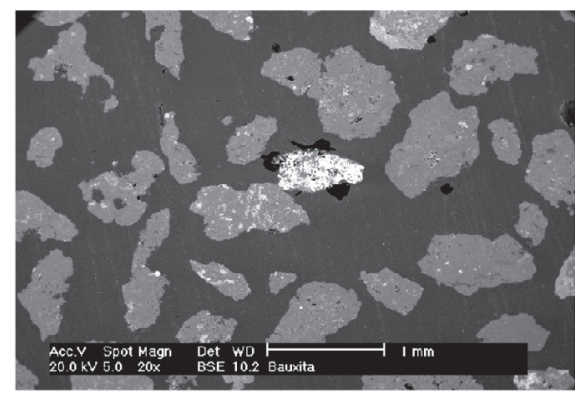

(a)

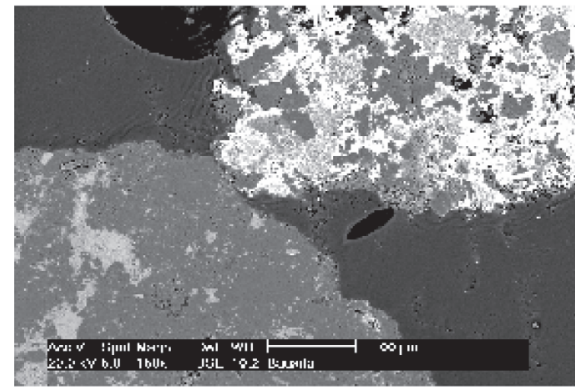

(b)

Figura 2. MEV da bauxita ativada: (a) 20x, e (b) 100x de aumento dem ser observadas distintas regiões, caracterizadas por tonalidades de branco e cinza.

Segundo a análise química por EED, Tabela 2, a fase branca da micrografia foi caracterizada pela presença de cério $(68,12 \%)$, a fase cinza dentro da fase branca caracterizada pela presença de alumínio (19,52\%), silício $(23,14 \%)$ e cério $(27,01 \%)$, a fase cinza escuro, por alumínio $(76,75 \%)$ e a fase cinza claro, por ferro $(66,35 \%)$. Tais resultados correspondem, parcialmente, às fases identificadas por DRX e à análise por FRX. A presença de compostos de cério é pontual, já que não foram detectadas quantidades significativas deste elemento nas demais análises realizadas.

\section{Classificação de resíduos sólidos}

Quanto aos parâmetros avaliados no teste de lixiviação, Tabela 3 , a amostra ensaiada apresentou resultados abaixo daqueles relacionados na Listagem 7 da NBR 10004. ${ }^{9}$ Nos valores obtidos para os itens indicados no teste de solubilidade, o resultado encontrado para fenol apresentou-se acima dos valores indicados na Listagem 8 da NBR 10004. ${ }^{9}$ Já na massa bruta, o valor encontrado para hidrocarbonetos (na forma de óleos e graxas) apresentou-se acima daquele indicado na Listagem 9 da NBR 10004. ${ }^{9}$ Portanto, essa amostra é classificada como resíduo classe I (resíduo perigoso).

Para que o resíduo seja considerado perigoso ou Classe I, basta que seja identificada uma das seguintes características: inflamabilidade, corrosividade, reatividade, toxicidade ou patogenicidade. Como no presente caso, sendo encontrada uma delas, o resíduo deverá seguir um padrão de coleta, transporte, tratamento e disposição final diferenciados.

\section{Densidade, porosidade e distribuição granulométrica}

A densidade picnométrica determinada para a amostra de bauxita ativada foi de $2,60 \mathrm{~g} / \mathrm{cm}^{3}$. Este valor situa-se na faixa indicada na literatura. ${ }^{7}$ A densidade das bauxitas porosas e pobres em sílica é de $1,2 \mathrm{~g} / \mathrm{cm}^{3}$, enquanto que nas bauxitas densas e ricas em ferro atinge $3,5 \mathrm{~g} / \mathrm{cm}^{3}$.

A amostra de bauxita ativada apresentou porosidade igual a $40,1 \%$ e diâmetro médio de poro igual a $0,082 \mu \mathrm{m}$. A amostra de bauxita ativada impregnada com óleo mineral isolante apresentou porosidade igual a $15,0 \%$ e diâmetro médio de poro igual a 0,405 $\mu \mathrm{m}$. Esses resultados indicam o grau de saturação dos poros pelo óleo isolante.

A amostra apresenta uma distribuição granulométrica de acordo com a especificação técnica de bauxitas ativadas para regeneração de óleo mineral isolante, ou seja, máximo de 5,0\% na peneira de 20 mesh (no presente caso, 1,9\%), mínimo de $95,0 \%$ na peneira de 60 mesh (neste caso, 97,5\%), e máximo 2,0\% de finos (para a amostra analisada: $0,2 \%<53 \mu \mathrm{m}$ ou passante na peneira de 270 mesh).

\section{Área superficial e adsorção em azobenzeno}

Os valores de área superficial BET foram $74,7 \mathrm{~m}^{2} / \mathrm{g}$ para a amostra de bauxita ativada e $5,96 \mathrm{~m}^{2} / \mathrm{g}$, para a amostra de bauxita ativada impregnada. Tal diferença corresponde à diminuição de superfície livre, devida à adsorção do mineral isolante.

Uma solução de $1 \%$ de azobenzeno em isooctano foi percolada através de $20 \mathrm{~g}$ de bauxita ativada contida em uma coluna de vidro. A quantidade de líquido incolor recuperado na parte inferior da coluna é a medida da atividade de adsorção da bauxita ativada. Neste ensaio, utilizou-se bauxita ativada com teor de umidade igual a $2 \%$ e bauxita ativada seca em estufa a $100{ }^{\circ} \mathrm{C}$ por $20 \mathrm{~h}$.

A bauxita ativada úmida apresentou resultado de adsorção por azobenzeno igual a $3 \mathrm{~mL}$, e a bauxita ativada seca apresentou re- 
Tabela 3. Análise da bauxita ativada impregnada com óleo mineral isolante segundo a norma NBR $10004^{9}$

\begin{tabular}{|c|c|c|c|c|c|c|}
\hline \multirow[t]{2}{*}{ Determinação } & \multicolumn{2}{|c|}{ Lixiviado } & \multicolumn{2}{|c|}{ Solubilizado } & \multicolumn{2}{|c|}{ Amostra Bruta } \\
\hline & $\begin{array}{c}\text { Resultado } \\
\text { Obtido } \\
(\mathrm{mg} / \mathrm{L})\end{array}$ & $\begin{array}{c}\text { Valor }(*) \\
\text { Listagem } 7 \\
(\mathrm{mg} / \mathrm{L})\end{array}$ & $\begin{array}{c}\text { Resultado } \\
\text { Obtido } \\
(\mathrm{mg} / \mathrm{L})\end{array}$ & $\begin{array}{c}\text { Valor }(*) \\
\text { Listagem } 8 \\
(\mathrm{mg} / \mathrm{L})\end{array}$ & $\begin{array}{l}\text { Resultado } \\
\text { Obtido } \\
(\mathrm{mg} / \mathrm{kg})\end{array}$ & $\begin{array}{c}\text { Valor }(*) \\
\text { Listagem } 9 \\
(\mathrm{mg} / \mathrm{kg})\end{array}$ \\
\hline Umidade & & & & & $1,54 \%$ & \\
\hline Fenol & & & 0,41 & 0,001 & 1,20 & 10 \\
\hline Surfactantes & & & $<0,1$ & 0,2 & & \\
\hline $\mathrm{pH}$ & & & 7,6 & & 7,4 & $>2,<12,5$ \\
\hline Berílio & & & & & $<1$ & 100 \\
\hline Arsênio & $<0,05$ & 5,0 & $<0,05$ & 0,05 & $<0,5$ & 1000 \\
\hline Cádmio & $<0,05$ & 0,5 & $<0,005$ & 0,005 & & \\
\hline Chumbo & $<0,05$ & 5,0 & $<0,05$ & 0,05 & 23,0 & 1000 \\
\hline Bário & 0,14 & 100 & $<0,1$ & 1,0 & & \\
\hline Crômio VI & & & & & $<0,5$ & 100 \\
\hline Crômio Total & $<0,05$ & 5,0 & $<0,05$ & 0,05 & & \\
\hline Sódio & & & 3,72 & 200 & & \\
\hline Vanádio & & & & & 7,09 & 1000 \\
\hline Manganês & & & $<0,1$ & 0,1 & & \\
\hline Selênio & $<0,01$ & 0,1 & $<0,01$ & 0,01 & $<0,5$ & 100 \\
\hline Prata & $<0,05$ & 5,0 & $<0,05$ & 0,05 & & \\
\hline Ferro & & & $<0,1$ & 0,3 & & \\
\hline Cobre & & & $<0,1$ & 0,1 & & \\
\hline Mercúrio & $<0,05$ & 0,1 & $<0,001$ & 0,001 & $<0,5$ & 100 \\
\hline Zinco & & & $<0,1$ & 5,0 & & \\
\hline Alumínio & & & $<0,1$ & 0,2 & & \\
\hline Nitrato $(\mathrm{N})$ & & & $<0,1$ & 10 & & \\
\hline Fluoreto & $<0,1$ & 150 & 0,22 & 1,5 & & \\
\hline Cianetos & & & $<0,1$ & 0,1 & $<0,5$ & 1000 \\
\hline Sulfatos & & & 19 & 400 & & \\
\hline Cloretos & & & 18 & 250 & & \\
\hline Dureza $\left(\mathrm{CaCO}_{3}\right)$ & & & 10 & 500 & & \\
\hline $\begin{array}{l}\text { Hidrocarbonetos } \\
\text { (óleos/graxas) }\end{array}$ & & & & & $16,3 \%$ & $5 \%$ \\
\hline
\end{tabular}

(*) Valores máximos indicados no Anexo II da NBR 10004. ${ }^{9}$

sultado adsorção por azobenzeno igual a $47 \mathrm{~mL}$. O valor mínimo de adsorção por azobenzeno para a bauxita ativada, especificado pelo fabricante da bauxita ativada, é igual a $14 \mathrm{~mL}$. Observou-se que a eficiência de adsorção da bauxita ativada é reduzida significativamente quando a bauxita ativada está úmida.

\section{Análise térmica}

A partir das curvas de análise térmica da bauxita ativada, Figura 3 , constatou-se perda de massa igual a $8,76 \%$, devido à umidade presente na amostra e à desidroxilação. Inicialmente a perda de água de $4,34 \%$ produziu um pico endotérmico a $119,4{ }^{\circ} \mathrm{C}$. A gibsita e a boemita dão bandas endotérmicas de desidroxilação entre 300

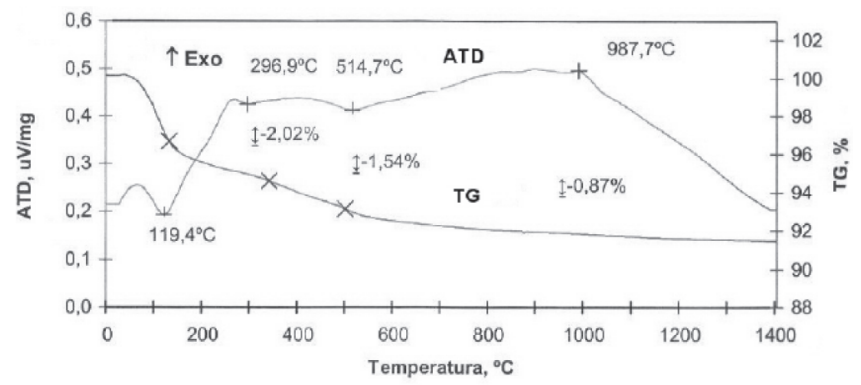

Figura 3. ATD/TG da bauxita ativada e $550{ }^{\circ} \mathrm{C}$, respectivamente. ${ }^{7}$ As reações térmicas da gibsita dependem de muitas variáveis, como o tamanho do cristal da gibsita, a atmosfera e a taxa de aquecimento. A boemita, $\mathrm{AlOOH}-\gamma$, é transformada por aquecimento a aproximadamente $430{ }^{\circ} \mathrm{C}$ para $\mathrm{Al}_{2} \mathrm{O}_{3}$ $\gamma$. Acima de $950{ }^{\circ} \mathrm{C}$, os cristais de $\mathrm{Al}_{2} \mathrm{O}_{3}-\gamma$ aumentam de tamanho conduzindo à formação de $\mathrm{Al}_{2} \mathrm{O}_{3}-\delta$ e $\theta$. Aquecimento superior a $1000{ }^{\circ} \mathrm{C}$ produz $\mathrm{Al}_{2} \mathrm{O}_{3}-\alpha$. Correspondentemente, identificam-se picos endotérmicos nas temperaturas de 296,9 e $514,7^{\circ} \mathrm{C}$ e um pico exotérmico na temperatura de $987,7^{\circ} \mathrm{C}$.

$\mathrm{Na}$ Figura 4, análise térmica da bauxita impregnada com óleo, observa-se uma perda de massa igual a $24,32 \%$ no intervalo de temperatura de 25,6 a $1400{ }^{\circ} \mathrm{C}$. A perda de $16,95 \%$ é referente à perda de água, desidroxilação e volatilização do óleo mineral isolante. $\mathrm{O}$ óleo mineral isolante quando aquecido, em presença de oxigênio, acima de $200{ }^{\circ} \mathrm{C}$ gera vapor de água, e acima de $400{ }^{\circ} \mathrm{C}$ origina metano, etano, etileno e dióxido de carbono. ${ }^{20}$

\section{Gresificação}

No processamento cerâmico tradicional ou triaxial, ao serem atingidas temperaturas mais elevadas do ciclo de queima, parte da massa cerâmica se transforma em um líquido viscoso que escoa e ocupa os espaços vazios entre as partículas mais refratárias, reduzindo a porosidade e promovendo a aproximação das partículas, levando à retração. Durante o resfriamento, esse material líquido 


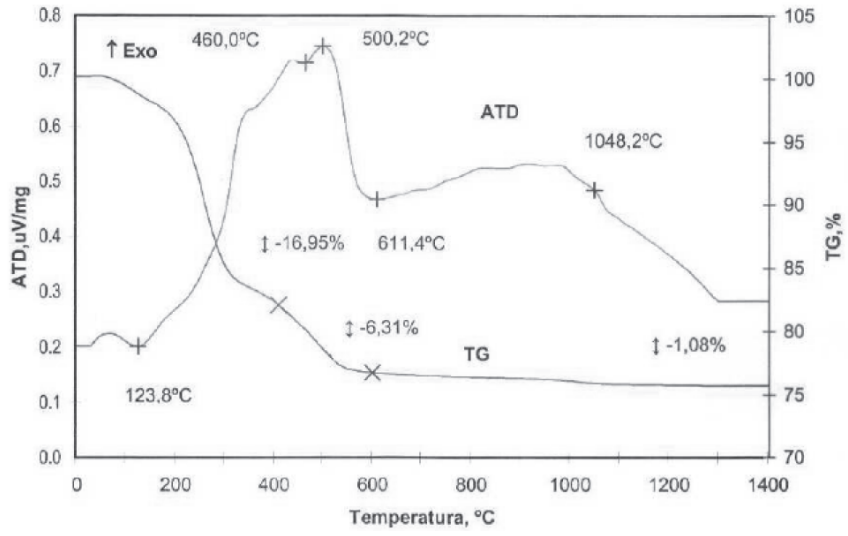

Figura 4. ATD/TG da bauxita ativada impregnada com óleo mineral isolante

se transforma em um vidro que liga as partículas mais refratárias, aumentando a resistência mecânica do material cerâmico. ${ }^{13}$

Assim, duas das principais variações sofridas pelo corpo cerâmico durante a queima são a diminuição da porosidade, caracterizada pela diminuição da absorção de água, e a redução de volume, caracterizada pela retração linear. Considerando os valores de retração de queima e absorção de água até $1200{ }^{\circ} \mathrm{C}$, Tabela 4, observa-se que a bauxita ativada não sofre modificações significativas, caracterizando-se como material refratário nesta faixa de temperatura,

Tabela 4. Retração linear e absorção de água da bauxita em função da temperatura de queima

\begin{tabular}{lcc}
\hline $\begin{array}{l}\text { Temperatura de } \\
\text { queima, }{ }^{\circ} \mathrm{C}\end{array}$ & Retração linear,\% & Absorção de água,\% \\
\hline 1000 & 0,4 & 28,7 \\
1050 & 0,5 & 29,1 \\
1100 & 0,7 & 29,4 \\
1150 & 1,2 & 30,0 \\
1200 & 1,7 & 30,4 \\
\hline
\end{tabular}

\section{CONCLUSÕES}

A bauxita analisada apresenta teores majoritários de Al, Si e $\mathrm{Fe}$, que correspondem às fases cristalinas gibsita, boemita, alumina e hematita. Além disso, fases de aluminossilicatos amorfos ou pouco cristalinos estão também presentes.

A bauxita impregnada com óleo mineral isolante foi classificada como resíduo classe I (resíduo perigoso), devido à presença de fenol e hidrocarbonetos acima dos valores prescritos pela norma NBR 100004, listagens 8 e 9, respectivamente. Por esse motivo, os cuidados com a estocagem, transporte e manuseio devem receber atenção especial no sentido de prever uma solução segura e confiável a este resíduo.

Os valores de densidade, distribuição granulométrica e adsorção da bauxita ativada encontram-se dentro da faixa especificada para aplicação como adsorvente de óleo mineral isolante.

A análise térmica e as curvas de gresificação indicam que a bauxita apresenta características correspondentes a uma matéria-prima cerâmica refratária. No entanto, o teor relativamente alto de ferro e a presença de fenol e hidrocarbonetos são fatores que geram a necessidade de estudos complementares para permitir o uso deste resíduo como matéria-prima alternativa na indústria cerâmica.

\section{REFERÊNCIAS}

1. Luz Jr., G. E.; Guimarães Neto, J. M.; Moita Neto, J. M.; Quim. Nova 2005, $28,535$.

2. Zirbes, R.; Rolim, J. G.; Zurn, H. H.; SBA Controle \& Automação 2005, $16,318$.

3. Mitchinson, P. M.; Hosier, I. L.; Lewin, P. L.; Vaughan, A. S.; Chen, G. C.; Jarman, P.; IEEE International Symposium on Electrical Insulation Proceedings 2007, 1, 89.

4. Wasserberg, V.; Borsi, H.; Gockenbach, E.; IEEE International Symposium on Electrical Insulation Proceedings 2007, 1, 233.

5. Pahlavanpour, E.; Martins, M. A.; IEEE Electrical Insulation Conference Proceedings 2003, 1, 283.

6. Saha, T. K.; Darveniza, M.; Yao, Z. T.; Hill, D. J. T.; Young, G.; IEEE Transactions on Power Delivery 1999, 14, 1359.

7. Santos, P. S.; Ciência e Tecnologia das Argilas, $2^{\mathrm{a}}$ ed., Edgard Blücher: São Paulo, 1992, vol. 2, cap. 28.

8. Karaulic, D.; Kotlica, M.; Karaulic, B.; IEEE Electrical Insulation Conference Proceedings 1999, 1, 317.

9. Associação Brasileira de Normas Técnicas; NBR 10004: Resíduos Sólidos - Classificação, 2004

10. Associação Brasileira de Normas Técnicas; NBR 10005: Procedimento para Obtenção de Extrato Lixiviado de Resíduos Sólidos, 2004.

11. Associação Brasileira de Normas Técnicas; NBR 10006: Procedimento para Obtenção de Extrato Solubilizado de Resíduos Sólidos, 2004.

12. Associação Brasileira de Normas Técnicas; NBR 10007: Amostragem de Resíduos Sólidos, 2004.

13. Melchiades, F. G.; Quintero, E.; Boschi, A. O.; Cerâmica Industrial 1996, 1,31 .

14. Pascoal, C.; Pandolfelli, V.; Cerâmica 2000, 46, 76.

15. Pascoal, C.; Pandolfelli, V.; Cerâmica 2000, 46, 131.

16. Sehnke, E. D.; Proceedings of UNITECR'93 1993, 1, 658.

17. Tanno, L. C.; Motta, J. F. M.; Cerâmica Industrial 2000, 5, 37.

18. Silva Filho, J. G.; Dissertação de Mestrado, Universidade de São Paulo, Brasil, 1971.

19. Pascoal, C.; Machado, R.; Pandolfelli, V.; Cerâmica 2002, 48, 61.

20. Milash, M.; Manutenção de Transformadores em Líquido Isolante, Edgard Blücher: São Paulo, 1984. 